\title{
ALÍQUOTA EFETIVA DE TRIBUTOS SOBRE O LUCRO NO BRASIL DAS COMPANHIAS DA B3: UM ESTUDO DA RELAÇÃO DOS INDICADORES DE RETORNO FINANCEIRO ${ }^{1}$
}

\author{
Tiago de Jesus Mendes ${ }^{2}$ \\ Ilva Ruas Abreu \\ Felipe Fróes Couto
}

\begin{abstract}
RESUMO
A relação dos indicadores de retorno financeiro das empresas do Brasil, Bolsa, Balcão-B3, com o gerenciamento da alíquota efetiva de tributos sobre o lucro, influenciou a pesquisa. Para isso, identificou-se a relação dos indicadores financeiros de retorno sobre o patrimônio-ROE e o retorno sobre o capital investido- ROIC com a alíquota efetiva dos tributos sobre o lucro. A pesquisa possui característica explicativa e utilizou-se de regressão com dados em painel para analisar os resultados. Como resultado, o ROIC demonstrou que possivelmente as empresas mais rentáveis possuem maiores alíquotas efetivas dos tributos. O ROE apresentou que, possivelmente, o investimento da organização na remuneração por desempenho dos diretores, os leva a investirem mais recursos no gerenciamento tributário, gerando um aumento do retorno para os acionistas. A alavancagem financeira indica que no Brasil uma estrutura alavancada, pode contribuir para uma maior carga fiscal, levando as empresas a aumentarem as participações de capitais de terceiros, neutralizando o efeito da alavancagem sobre a tributação. O tamanho da empresa pode indicar que quanto maior o tamanho da empresa menor o imposto sobre o lucro da empresa. Como resultado para a taxa de imposto efetiva identificou-se que as empresas utilizam os benefícios da redução da alíquota efetiva dos tributos sobre o lucro, pois o teste não paramétrico de sinais demonstrou que em $80 \%$ das observações, as alíquotas efetivas dos tributos das empresas analisadas são menores que a alíquota nominal de $34 \%$, logo as empresas utilizam os efeitos do gerenciamento tributário.
\end{abstract}

Palavras-chave: Indicadores de retorno financeiro das empresas. Gerenciamento tributário. Alíquota efetiva de tributos sobre o lucro.

\section{Effective tax rate on profit in Brazil of $\mathrm{B} 3$ companies: a study of the relationship of}

\section{financial return indicators}

\begin{abstract}
The list of financial return indicators for companies in Brazil, Bag, Counter-B3, with the management of the effective tax rate on profit, influenced the research. For this, the relationship between the financial indicators of return on equity-ROE and the return on invested capitalROIC was identified with the effective rate of taxes on profit. The research has an explanatory characteristic and regression with panel data was used to analyze the results. As a result, ROIC

${ }^{1}$ Como citar este artigo:

MENDES, T. de J.; ABREU, I. R.; COUTO, F. F. Alíquota efetiva de tributos sobre o lucro no Brasil das companhias da B3: um estudo da relação dos indicadores de retorno financeiro. ForScience, Formiga, v. 8, n. 2 , e00776, jul./dez. 2020. DOI: 10.29069/forscience.2020v8n2.e776.

${ }^{2}$ Autor para correspondência: Tiago de Jesus Mendes, e-mail: tjmendes91@gmail.com
\end{abstract}


has shown that possibly the most profitable companies have higher effective tax rates. The ROE showed that possibly the organization's investment in the payment per directors performance leads them to invest more resources in the tax management, generating an increase to the shareholders' return. Financial leverage indicates that in Brazil a leveraged structure can contribute to a greater tax burden, leading companies to increase the holdings of third-party capital, neutralizing the effect of leverage on taxation. The size of the company may indicate that the larger the company size, the smaller the company's profit tax. As a result to the effective tax rate, was identified that the enterprises they use the benefits of reducing the effective tax rate on profit, since the non- parametric signal test demonstrated that in $80 \%$ of the observations, the effective rate of the analyzed companies are lower than the nominal rate of $34 \%$, soon the companies to use the effects of tax management.

Keywords: Indicators of financial return of companies. Tax management. Effective tax rate income.

\section{INTRODUÇÃO}

As leis tributárias brasileiras estão em constantes mudanças, provocando preocupações paras as empresas instaladas no país e para os cidadãos que residem nele. Segundo Utzig et al. (2014), a carga tributária do Brasil impacta diretamente no consumo das famílias e contribui para impedir investimentos diretos na economia nacional, pois para os investidores é o principal mecanismo que influencia na redução da rentabilidade das empresas. Aliás, incentiva as empresas a implantarem um rigoroso controle tributário por meio da gestão tributária, que possui a finalidade de economizar de forma legal o ônus da carga tributária brasileira.

Estudos na área como Zimmermann (1983); Shevlin (1999); Rego (2003); Tang (2005); Dryeng, Hanlon e Maydew (2008); Armstrong, Blouin e Larcker (2012) e Guenther, Matsunaga e Williams (2013), afirmam que o gerenciamento tributário das empresas pode ser medido por meio de três proxies, Effetive Taxe Rate (ETR), Cash Effetive Taxe Rate (CashETR) e BookTax Differences (BTD).

A ETR mede o índice de impostos pagos sobre a renda e informa o efeito cumulativo de vários incentivos fiscais. A CashETR é usada para investigar a economia de impostos pagos pelas empresas a longo prazo e a BTD abrange a diferença entre o lucro contábil e lucro tributável, quando o lucro tributável é menor, maior a possibilidade de gerenciamento tributário.

Nesta pesquisa a proxy utilizada para medir o nível de gerenciamento tributário foi a ETR, que segundo Guimarães, Macedo e Cruz (2015) uma das possibilidades de investigar de forma empírica o comportamento do gerenciamento tributário é a avaliação da alíquota efetiva de imposto ou Effective Taxe Rate (ETR). 
A hipótese da pesquisa é analisar se os indicadores de retorno financeiro das empresas da B3 possuem relação com a ETR evidenciando uma redução ou aumento da alíquota dos tributos sobre a renda e o lucro líquido. O objetivo geral busca analisar a relação dos indicadores de retorno financeiro das empresas da B3, com o gerenciamento da alíquota efetiva dos tributos sobre o lucro.

A justificativa para analisar a taxa efetiva de impostos sobre o lucro- ETR e a relação com os indicadores de retorno financeiro: retorno sobre o patrimônio líquido (ROE) e o retorno sobre o capital investido (ROIC) é que os principais interessados na maximização do retorno financeiro das empresas são os acionistas e o gerenciamento da alíquota efetiva sobre o lucro é uma forma de melhorar os resultados financeiros das organizações.

Existe uma literatura significativa que procura associar os índices financeiros com os indicadores de planejamento tributário, como por exemplo, Huang, Wang e Tsai (2016), evidenciam que os ETRs estão relacionados com características específicas das empresas (tamanho da empresa, rentabilidade, intensidade de capital, alavancagem, despesas com pesquisa e desenvolvimento e incentivos fiscais) e características da indústria.

Os autores Guenther, Matsunaga e Williams (2013), utilizaram para explicar os determinantes do planejamento fiscal, agressividade e riscos fiscais o ativo total e imobilizado, vendas externas, pesquisa e desenvolvimento, ativo intangível, o benefício fiscal de opções de ações e a dívida de longo prazo.

As estratégias das empresas para aumentar o retorno sobre o capital próprio e o retorno sobre o capital investido, está continuamente ligada a ações de gerenciamento dos custos, que segundo Siqueira, Cury e Gomes (2011) a redução dos custos é uma necessidade constante em todas as empresas brasileiras visto que as mesmas estão em um ambiente de alta competitividade.

Ao abordar os indicadores de retorno ROE e ROIC é possível analisar a variação do retorno financeiro para os acionistas ordinários da empresa e os investidores externos por meio da variação da alíquota efetiva dos tributos sobre o lucro, sendo que uma alíquota inferior a $34 \%$ indica que as empresas utilizam alguma forma gerenciamento tributário, pois mesmo que a ETR sofra influência das compensações de prejuízos fiscais, no Brasil diferente dos demais países, o Decreto-Lei n. 2.341/1987 dispõe sobre as regras para compensação de prejuízo fiscal, que define os limites para a utilização desse mecanismo no país. 


\section{REVISÃO DA LITERATURA}

\subsection{Gerenciamento Tributário e Alíquota Efetiva de Tributos (ETR)}

A gestão dos impostos é definida como a capacidade de pagar uma quantidade menor de impostos por um longo período de tempo. A gestão tributária não possui necessariamente relação com o comportamento antiético ou ilícito, sendo que os códigos tributários possuem dispositivos que aceitam a redução legal dos impostos pelas empresas (MINNICK; NOGA, 2010).

A Lei possui três interpretações para o ato de gerenciamento tributário, cujo nome é elisão fiscal, evasão fiscal e elusão fiscal. A elisão fiscal representa a economia de tributos de forma lícita. Segundo Fabretti (2001), é a escolha de um ato baseado na obediência de leis, para impedir o acontecimento do fato gerador de tributos, que é um gerenciamento tributário para a redução dos tributos. Para o autor, ela é legítima e lícita, pois a decisão é conforme o ordenamento jurídico, preferindo-se a alternativa legal com o menor custo ou aproveitando-se das brechas da lei.

A evasão fiscal de acordo com Higuchi (2014) no meio jurídico é conceituada como uma prática contrária à lei, com o propósito de não pagar tributo ou contribuição ou de diminuir o seu valor, sendo uma ação realizada com transgressão de lei porque é subsequente ao acontecimento do fato gerador do tributo.

A elusão fiscal (elisão ineficiente ou elisão abusiva), o contribuinte cria uma transação jurídica com a intenção de dissimular a realização do fato que gerou o tributo. Refere-se a uma estratégia marcada previamente com indícios de excessos das formas do direito, pois o sujeito passivo escolhe uma forma jurídica atípica, dentro da lei, com o objetivo de evadir, disfarçadamente, da tributação para recolher menos tributo (MINARDI, 2015; ALEXANDRE, 2016).

A Alíquota Efetiva de Tributos (ETR) informa para as empresas a alíquota gerada pelas despesas com imposto sobre a renda e o lucro líquido. Quando as empresas utilizam alguma estratégia para reduzir o tributo, ela indica se a empresa realiza um gerenciamento tributário.

Segundo Rego (2003) quando duas empresas possuem a mesma renda contábil antes de impostos sobre a renda e o lucro líquido, mas pagam diferentes valores de tributos, a empresa que paga menos tributos possui uma ETR menor e será identificada como mais efetiva no gerenciamento tributário. 
A alíquota efetiva de tributo média (ETR) é o quociente em porcentagem da despesa de imposto de renda e o lucro líquido pela receita antes de impostos durante o ano. É um indicador da carga tributária e reflete o impacto de incentivos fiscais e taxa de imposto paga (HUANG; WANG; TSAI, 2016).

\subsection{Indicadores de Retorno Financeiro e de Estrutura de Capital}

A rentabilidade indica o desempenho de uma empresa, ou seja, é uma ferramenta que ajuda mostrar a capacidade da empresa em gerar retornos financeiros para os acionistas. Segundo Padoveze (2010), a rentabilidade apresenta os ganhos ou perdas das empresas em certo período, envolvendo os elementos operacionais, econômicos e financeiros do negócio.

Segundo Damodaran (2004) o ROE mostra a rentabilidade baseada nos interesses do investidor em ações, associando os lucros ao investidor em ações (lucro líquido após os impostos e despesas de juros) com o valor contábil das aplicações em ações. O cálculo do ROE é igual ao lucro líquido dividido pelo patrimônio líquido.

Conforme Assaf Neto (2014), o ROIC é constituído pelos recursos (passivos) onerosos adquiridos por uma organização (empréstimos e financiamentos) e os recursos próprios investidos pelos proprietários no patrimônio líquido. Indicando o retorno do capital de terceiros sobre os lucros da empresa, ROIC é igual NOPAT dividido pelo valor contábil do investimento.

Os indicadores de estrutura de capital descrevem a composição (estrutura) das fontes de obrigações de uma empresa. Demonstram como os recursos de terceiros utilizados pela organização relacionam com a sua participação em relação ao capital próprio. Permite avaliar o nível de endividamento financeiro de uma empresa diante de seus credores (principalmente instituições financeiras) e sua competência de realizar compromissos financeiros de longo prazo (ASSAF NETO, 2014).

Os índices de estrutura de capital utilizados na pesquisa foram o índice de endividamento de longo prazo e o grau de alavancagem financeira. Segundo Damodaran (2004, p.104) "índices de endividamento tentam relacionar a dívida ao capital total ou ao patrimônio líquido”. Conforme Gitman (2010, p. 55), “o analista financeiro está mais preocupado com as dívidas de longo prazo porque elas comprometem a empresa com uma série de pagamentos contratuais ao longo do tempo".

Segundo Brealey, Myers e Allen (2013) a dívida pode aumentar os retornos dos acionistas em períodos em que o mercado está otimista ou reduzir em períodos em que a 
economia está em queda, gerando uma alavancagem financeira. Os índices dessa alavancagem medem o grau com que uma organização tenha adotado a alavancagem financeira.

\subsection{Evidências Empíricas}

Os estudos sobre as proxies para medir o nível de gerenciamento tributário das empresas no Brasil está em um estágio crescente, ao contrário dos Estados Unidos que há muitos anos estuda-se o gerenciamento tributário, pois as empresas estão preocupadas cada vez mais em reduzir o impacto das despesas com tributos e, consequentemente, em melhorar os seus resultados financeiros.

Gupta e Newberry (1997) examinaram a associação entre a ETR, tamanho da firma e variáveis proxies para estruturas de capital das empresas, mix de ativos e a rentabilidade das empresas. Os resultados sugerem que a ETR não está associada ao tamanho da empresa, quando a relação é examinada ao longo do tempo com empresas que têm histórias mais longas e também mostram que as ETRs estão sistematicamente relacionadas ao capital da firma, estrutura e mix de ativos.

Rego (2003) examina a ETR das empresas multinacionais dos Estados Unidos da América (EUA) em comparação com a ETR das empresas nacionais apenas no país. Concluiu que, após o controle de impostos antes de impostos renda, operações no exterior, membros da indústria, ano e localização geográfica, as maiores empresas têm maiores ETR.

Minick e Noga (2010) investigam como a governança corporativa desempenha um papel na gestão fiscal de longo prazo. Os resultados mostram problemas relacionados à remuneração dos executivos e dos diretores e mostram que incentivos na remuneração fornecem incentivos de longo prazo para melhorar o desempenho, pois existe uma relação de maior sensibilidade ao desempenho remunerado e impostos mais baixos. Encontrou-se que o incentivo a remuneração levam os gerentes a fazerem investimentos de longo prazo na gestão de impostos. Evidenciouse também que investimentos na gestão tributária beneficiam os acionistas; um melhor gerenciamento de impostos está positivamente relacionado a maiores retornos dos acionistas.

Armstrong, Blouin e Larcker (2012) examinaram a associação entre incentivos executivos e as taxas de imposto efetivas em dinheiro (ETR). Encontrou-se uma forte relação negativa entre os incentivos dos administradores fiscais e a medida da despesa tributária total por dólar de lucro contábil (ETRGAAP) e nenhuma relação entre incentivos dos 
administradores fiscais e o ETR do dinheiro. Esses resultados indicam que os administradores de impostos recebem incentivos para reduzir a despesa com impostos sobre a renda.

Gomes (2012) analisou se as características da governança corporativa influenciam o gerenciamento tributário das empresas brasileiras. Esse gerenciamento tributário foi medido por meio de três proxies: ETR, CashETR e BTD. Como resultado, constatou-se que as empresas brasileiras não ignoram os benefícios do gerenciamento tributário, já que tanto a ETR, como a CashETR, apresentou alíquotas efetivas de $25 \%$. Também a remuneração dos diretores executivos pode ser considerada como característica que influencia o gerenciamento tributário.

Utzig et al. (2014), verificou as empresas de capital aberto do setor da construção civil localizadas nos países do Mercosul, com o objetivo de identificar a taxa de imposto efetiva sobre a renda e o gerenciamento tributário nas empresas do setor de construção civil do Mercosul. Concluíram que somente nas empresas do setor de construção civil do Brasil há gerenciamento tributário para fins de diminuição dos impostos sobre a renda.

Guimarães, Macedo e Cruz (2015) analisaram a alíquota efetiva de tributos sobre o lucro de empresas de capital aberto atuantes, no Brasil, no período de 2003 e 2013, tanto em relação à alíquota efetiva total (ETRt) quanto à alíquota efetiva corrente (ETRc), buscando verificar indícios da presença de gerenciamento tributário. Os resultados evidenciaram indícios de prática de gerenciamento tributário e que os ajustes decorrentes do regime tributário de transição (RTT) implicaram em uma carga fiscal menor. Observou-se também que empresas de maior porte apresentam menor carga fiscal e que, em geral, as empresas adotam escolhas que permitem o deferimento dos tributos sobre o lucro.

Mota e Leite Filho (2017) em pesquisa realizada buscaram verificar quais fatores estão associados ao gerenciamento tributário, considerando a métrica de elisão fiscal, a Long-Run Cash ETR. Como resultados têm-se que as empresas investigadas pagam efetivamente impostos abaixo da alíquota de 34\% de Imposto de Renda e Contribuição Social sobre o Lucro Líquido, pressupondo a prática de gerenciamento tributário. Verificou-se também que apenas os ativos intangíveis apresentaram resultados condizentes com a literatura precedente.

O entendimento sobre a gestão tributária passa pela análise da legislação do país, pois é necessário conhecer como cada país administra o gerenciamento tributário, visto que as leis tributárias diferem entre os países. Como a pesquisa engloba os indicadores de retorno financeiro é importante conhecer, essas variáveis que foram utilizadas e os estudos sobre o tema, pois contribuem para analisar o problema de pesquisa por várias óticas e confirmar os resultados encontrados na pesquisa. 


\section{MATERIAL E MÉTODOS}

\subsection{Caracterização da Pesquisa}

A pesquisa quanto aos objetivos possui características explicativas. Conforme Andrade (2010, p.112) "a pesquisa explicativa além de registrar, analisar e interpretar os fenômenos estudados procura identificar seus fatores determinantes, ou seja, suas causas". A pesquisa analisa a relação dos indicadores de retorno financeiro das empresas da B3, com o gerenciamento da alíquota efetiva dos tributos sobre o lucro. Para isso, elaborou-se a hipótese com a utilização de teorias existentes que foram testadas com os recursos de modelos de regressão com dados em painel.

Segundo Gujarati e Porter (2011, p. 587) "nos dados em painel, a mesma unidade de corte transversal (uma família, uma empresa, um estado) é acompanhada ao longo do tempo. Em síntese, os dados em painel têm uma dimensão espacial e outro temporal". Segundo o autor acima os dados em painel aumentam a consistência da análise, gerando uma preferência a esta em relação a dados de séries temporais ou de corte transversal. "Os dados do painel são capazes de controlar essas variáveis invariantes de estado e tempo enquanto uma série de tempo ou um estudo transversal não pode" (BALTAGI, 2005, p. 5).

Segundo Gomes (2012) o teste não paramétrico de sinais possui a capacidade de indicar se a alíquota efetiva de tributos identificada por meio do cálculo da ETR é menor do que a alíquota nominal dos tributos sobre o lucro. Visto que também nessa pesquisa não se pode afirmar que a população tratada na pesquisa possui distribuição normal. Logo se optou por utilizar o método não paramétrico de teste de sinais como alternativa aos testes relativos a médias e aos testes relativos a diferenças entre médias.

De acordo com Gomes (2012, p. 83), "tal teste é aplicado quando se extrai amostras de uma população contínua, de modo que a probabilidade de obter um valor amostral menor do que a mediana e a probabilidade e obter um valor amostral maior do que a mediana são ambas de 50\%". O teste de sinais permite identificar duas situações diferentes. Ainda segundo Larson e Farber (2010, p. 486):

Para usar o teste de sinais, primeiro compare cada entrada na amostra com a mediana hipotética $k$. Se a entrada está abaixo da mediana, designe um sinal -, se a entrada está acima da mediana, designe um sinal +; e se a entrada for igual à mediana, designe um 0 (zero). Então, compare o número dos sinais - e + (os 0 são ignorados). Se houver uma grande diferença entre o número de sinais + e o número de sinais -, é provável que a mediana seja diferente do valor hipotético e a hipótese nula deve ser rejeitada. 
O teste de sinais aponta se os resultados da amostra são diferentes do parâmetro da hipótese que está sendo utilizada para apontar se os resultados encontrados são maiores, menores ou iguais à hipótese que está se testando.

\subsection{Técnicas para Coleta de Dados}

A estratégia de pesquisa utilizada para reunir os dados foi a documental, que segundo Martins e Theóphilo (2009, p. 55) "as fontes documentais, além de permitirem a análise do perfil do profissional ao longo do tempo, evitam vieses que poderiam surgir caso se buscasse as informações diretamente nas empresas".

A pesquisa foi estruturada da seguinte maneira:

a) Identificação das variáveis: Lucro líquido antes dos tributos sobre a renda (LAIR) e despesas com tributos sobre a renda e contribuição social (IR \& CS). Ressalta-se que, com base nessas duas variáveis, calculou-se a proxy de identificação do gerenciamento tributário das empresas por meio da divisão das despesas com os tributos sobre o lucro (correntes e diferidas) pelo LAIR para encontrar o valor da ETR de cada empresa do campo de análise. Para a correlação entre indicadores de desempenho financeiro e o gerenciamento tributário, identificaram-se: a rentabilidade do patrimônio líquido (ROE), a rentabilidade do capital investido (ROIC), o ativo total, alavancagem financeira das empresas e o endividamento de longo prazo por meio dos índices financeiros e demonstrações contábeis disponibilizados na plataforma do Economatica.

b) Revisão conceitual das variáveis: referencial teórico;

c) Instrumento de coleta de dados: pesquisa documental junto às demonstrações contábeis e indicadores financeiros das empresas listadas na B3, extraindo-se as variáveis identificadas no item "a" acima do banco de dados da Economatica. Todos esses dados foram listados em uma planilha Excel, dando lhes uma estrutura de dados em painel, ou seja, uma lista de informações entre empresas (cross-section) e anos (series temporais - 2007 a 2016). Depois para a obtenção dos resultados estatísticos utilizou o software estatístico stata 12.

O cálculo da ERT é baseado na divisão da despesa tributária total pelo imposto de renda e contribuição social e lucro antes do imposto de renda (LAIR), que é o mesmo cálculo utilizado por Tang (2005). A identificação do gerenciamento tributário foi baseada no cálculo da ETR extraído das empresas listadas na B3. 
O parâmetro utilizado para identificar se as empresas adotam alguma forma de gestão tributária foi à alíquota nominal de $34 \%$ do imposto sobre a renda de pessoa jurídica (IRPJ), que segundo Young (2012) é formada pela alíquota do IRPJ de 15\%, aplicada sobre a totalidade da base de cálculo apurada, mais a adição da alíquota do IRPJ de 10\%, aplicada a parcela da base de cálculo que exceder ao limite de $\mathrm{R} \$ 20.000,00$ mensais, mais a aplicação da alíquota de 9\% da contribuição social sobre o lucro líquido (CSLL), totalizando 34\%.

\begin{tabular}{|c|c|c|}
\hline Setor Econômico & Subsetor & Total Geral \\
\hline Petróleo, Gás e Biocombustíveis & Petróleo, Gás e Biocombustíveis & 2 \\
\hline \multirow{5}{*}{ Materiais Básicos } & Mineração & 3 \\
\hline & Siderurgia e Metalurgia & 7 \\
\hline & Químicos & 3 \\
\hline & Madeira e Papel & 6 \\
\hline & Embalagens & 1 \\
\hline \multirow{6}{*}{ Bens Industriais } & Construção e Engenharia & 4 \\
\hline & Material de Transporte & 5 \\
\hline & Máquinas e Equipamentos & 4 \\
\hline & Transporte & 12 \\
\hline & Serviços Diversos & 3 \\
\hline & Comércio & 2 \\
\hline \multirow{5}{*}{ Consumo não Cíclico } & Agropecuária & 2 \\
\hline & Alimentos Processados & 7 \\
\hline & Bebidas & 1 \\
\hline & Produtos de Uso Pessoal e de Limpeza & 1 \\
\hline & Comércio e Distribuição & 1 \\
\hline \multirow{8}{*}{ Consumo Cíclico } & Construção Civil & 13 \\
\hline & Tecidos, Vestuário e Calçados & 11 \\
\hline & Utilidades Domésticas & 2 \\
\hline & Automóveis e Motocicletas & 2 \\
\hline & Mídia & 1 \\
\hline & Viagens e Lazer & 1 \\
\hline & Diversos & 1 \\
\hline & Comércio & 8 \\
\hline \multirow{4}{*}{ Saúde } & Medicamentos e Outros Produtos & 1 \\
\hline & Serviços Médico-Hospitalares, Análises e Diagnósticos & 2 \\
\hline & Equipamentos & 1 \\
\hline & Comércio e Distribuição & 3 \\
\hline \multirow{2}{*}{ Tecnologia da Informação } & Computadores e Equipamentos & 1 \\
\hline & Programas e Serviços & 1 \\
\hline Telecomunicações & Telecomunicações & 4 \\
\hline \multirow{3}{*}{ Utilidade Pública } & Energia Elétrica & 32 \\
\hline & Água e Saneamento & 3 \\
\hline & Gás & 2 \\
\hline Total & & 153 \\
\hline
\end{tabular}

Quadro 1- Amostra por Setor e Subsetor Econômico

Fonte: Autores (2018). 
A população deste trabalho é composta por todas as empresas cadastradas na B3 até 11 de novembro de 2017, consideradas no período de 2007 a 2016. O motivo para escolha desse período de análise se deve ao fato dos dados em painel utilizarem períodos de análise mais longos para aumentarem a consistência dos resultados e também foi identificado que os dados das demonstrações contábeis das empresas antes do período de 2007 não estavam distribuídos de forma homogênea, ou seja, algumas empresas não tinham os dados disponíveis ou não faziam parte da B3 no período anterior a 2007. Segundo Baltagi (2005), os dados do painel de macro, por outro lado, têm uma série de tempo mais longa e, ao contrário do problema de distribuições não padrão, típicas dos testes de raízes unitárias na análise de séries temporais.

As empresas que não tinham os dados disponíveis das variáveis no período analisado foram excluídas da pesquisa e as empresas do setor econômico financeiro e outros, pois a alíquota da CSLL de 15\% diferencia-se dos demais setores, que é de 9\%, além de adotarem procedimentos contábeis próprios desse setor na apuração do lucro. O setor outros também foi excluído devido à dificuldade de separá-lo do setor financeiro.

Conforme Vello e Martinez (2011) a exclusão dos dados busca dois objetivos: (1) alcançar uma organização das empresas, em dado setor e ano, com a finalidade de conseguir um erro menos significativo entre a carga tributária de um setor e o cálculo da média das cargas tributárias das empresas contidas; e (2) eliminar empresas sem bases comparáveis.

\subsection{Apresentação do Modelo e Descrição das Variáveis}

A hipótese da pesquisa refere se os indicadores de retorno financeiro das empresas da B3 possuem relação com a ETR, evidenciando uma redução ou aumento da alíquota do imposto sobre a renda e o lucro líquido. Acredita-se que as variáveis explicativas de retorno sobre o capital próprio e retorno sobre o capital investido estão relacionadas com a alíquota efetiva de impostos sobre o lucro.

O modelo básico utilizado para análise é:

$$
\mathrm{ETR} \text { it }=\beta_{1} \text { it }+\beta_{2} \text { it } \mathrm{ROE}+\beta_{3} \text { it ROIC }+\beta_{4} \text { it Tam }+\beta_{5} \text { it Alav }+\beta_{6} \text { it Endiv }
$$

Em que:

ETR = Taxa Efetiva de Imposto (ETR), que constitui a variável dependente do modelo; $\beta i=$ representa o coeficiente angular estimado para cada variável " $i$ " independente do modelo; As variáveis descritas a seguir, são as variáveis independentes do modelo:

$\mathrm{ROE}=$ Retorno sobre o patrimônio líquido; 
ROIC $=$ Rentabilidade do capital investido;

Tam = Logaritmo natural do ativo total da empresa, representando o tamanho da empresa;

As variáveis descritas abaixo são as variáveis de controle do modelo:

Alav = Grau de alavancagem financeira da empresa;

Endiv = Endividamento de longo prazo.

\begin{tabular}{|l|l|c|}
\hline Variável & \multicolumn{1}{|c|}{ Proxies } & Sinal Esperado \\
\hline Tam & Logaritmo natural do ativo total da empresa & - \\
\hline Alav & Grau de alavancagem financeira da empresa & - \\
\hline ROE & Retorno sobre o Patrimônio & - \\
\hline ROIC & Retorno sobre o Capital Investido & + \\
\hline Endiv & Endividamento de longo prazo & - \\
\hline
\end{tabular}

Quadro 2- Variáveis Explanatórias

Fonte: Autores (2018).

O retorno sobre o patrimônio líquido (ROE) relaciona-se com o nível da carga tributária, buscando priorizar o maior retorno para os acionistas, por meio da maximização da rentabilidade do investimento, sendo que um dos caminhos seria a redução dos impostos pagos. Segundo Perez, Serer e Molina Llopis (2005) o ROE oferece uma medida de renda obtida pelos acionistas.

O retorno sobre o capital investido (ROIC) interage com o grau de tributação das empresas, de forma semelhante ao retorno sobre o ativo das empresas, pois ele demonstra os retornos alcançados com os investimentos em ativos e a expectativa é que quanto maior os investimentos em ativos maiores serão a alíquota efetiva sobre a renda. Segundo Molina Llopis (2003, p. 201) "as empresas mais lucrativas são aquelas que têm os maiores lucros e, portanto, devem suportar uma carga tributária mais elevada".

A variável de tamanho é definida como o logaritmo natural dos ativos da empresa. A conversão no logaritmo natural é usada para obter uma distribuição mais equilibrada e evitar o potencial problema de não linearidade (CAO, 2012). Segundo Siegfried (1972) as maiores empresas podem ter mais recursos para influenciar a política fiscal e organizar suas operações de forma otimizada para economia dos impostos, reforçando a teoria do poder político.

Conforme Gupta e Newberry (1997) e Armstrong, Blouin e Larcker (2012) a alavancagem, mede a proporção da dívida de longo prazo da empresa para o total de ativos (LT / AT), é incluída para capturar a extensão do escopo fiscal da dívida. 
Ainda segundo Gupta e Newberry (1997) a alavancagem financeira é uma proxy para a estrutura de capital das empresas e está incluída para capturar decisões de financiamento das firmas. Para Gomes (2012) a alavancagem é uma variável que representa a busca pelos benefícios fiscais da dedução dos juros sobre a dívida com terceiros.

Segundo Cao (2012) a dívida é fundamental para a estrutura de capital da empresa e estão presentes no ambiente de quase todas as empresas, os juros das dívidas geralmente são dedutíveis de impostos, portanto, a dívida em estrutura de capital interfere de maneira negativa na ETR.

Conforme Gomes (2012) é relevante afirmar que, nessa pesquisa, entende-se que uma empresa é eficaz no gerenciamento tributário quando ela atinge menor alíquota efetiva de tributos sobre o lucro. Supõe- se que os indicadores financeiros, principalmente os de retornos financeiros estão relacionados com o nível de gerenciamento tributário. Ainda segundo Gomes (2012) assim sendo, o sinal esperado negativo, revela que aquela variável provavelmente reduzirá a alíquota efetiva da empresa, no entanto, o sinal positivo reflete que quanto maior aquela variável, maior será a alíquota efetiva.

\section{RESULTADOS E DISCUSSÃO}

\subsection{Gerenciamento Tributário - Taxa Efetiva- ETR}

A Tabela 1 representa a ETR das empresas por subsetor econômico, que compõem a amostra de 2007 a 2016 da B3. Depreende-se da tabela abaixo, que os subsetores econômicos no período de 2007 a 2016, que apresentaram os menores desvios padrões (DP) em relação à média foram de Produtos de Uso Pessoal e de Limpeza, Diversos e Gás. A alíquota média efetiva dos tributos desses subsetores econômicos foram 31,10\%, 27,4\% e 29,7\% indicando que elas se mantiveram homogêneas durante o período analisado.

Os demais setores apresentaram um desvio padrão com um alto grau de dispersão, onde não se pode afirmar que as alíquotas médias efetivas dos tributos por subsetores econômicos estão apresentadas na Tabela 1. Esses resultados indicam uma heterogeneidade entre as empresas analisadas, pois mesmo pertencendo, ao mesmo subsetor econômico cada uma possui uma política de gestão tributária particular. 
Tabela 1 - Alíquota média de 10 anos por Subsetor Econômico

\begin{tabular}{|c|c|c|c|c|}
\hline $\begin{array}{l}\text { ETR Subsetor } \\
\end{array}$ & Qtd & Média & Var. $^{1}$ & DP. $^{2}$ \\
\hline Petróleo, Gás e Biocombustíveis & 2 & 0,240 & 0,015 & 0,121 \\
\hline Mineração & 3 & 0,312 & 0,688 & 0,829 \\
\hline Siderurgia e Metalurgia & 7 & 0,143 & 0,084 & 0,289 \\
\hline Químicos & 3 & 0,120 & 0,804 & 0,896 \\
\hline Madeira e Papel & 6 & 0,151 & 1,076 & 1,037 \\
\hline Embalagens & 1 & 0,353 & 0,014 & 0,118 \\
\hline Construção e Engenharia & 4 & 0,303 & 0,734 & 0,856 \\
\hline Material de Transporte & 5 & 0,489 & 2,571 & 1,603 \\
\hline Máquinas e Equipamentos & 4 & 0,349 & 14,498 & 3,808 \\
\hline Transporte & 12 & 0,288 & 0,246 & 0,496 \\
\hline Serviços Diversos & 3 & 0,292 & 0,043 & 0,208 \\
\hline Comércio & 2 & 0,324 & 0,011 & 0,105 \\
\hline Agropecuária & 2 & 0,422 & 1,072 & 1,035 \\
\hline Alimentos Processados & 7 & 0,319 & 0,482 & 0,694 \\
\hline Bebidas & 1 & 0,212 & 0,009 & 0,092 \\
\hline Produtos de Uso Pessoal e de Limpeza & 1 & 0,310 & 0,003 & 0,051 \\
\hline Comércio e Distribuição & 1 & 0,580 & 2,406 & 1,551 \\
\hline Construção Civil & 13 & 0,134 & 0,210 & 0,459 \\
\hline Tecidos, Vestuário e Calçados & 11 & $-0,004$ & 0,986 & 0,993 \\
\hline Utilidades Domésticas & 2 & 0,189 & 0,019 & 0,137 \\
\hline Automóveis e Motocicletas & 2 & 0,315 & 0,055 & 0,234 \\
\hline Mídia & 1 & 0,137 & 0,041 & 0,202 \\
\hline Viagens e Lazer & 1 & 0,167 & 0,071 & $\overline{0,266}$ \\
\hline Diversos & 1 & 0,274 & 0,001 & 0,024 \\
\hline Comércio & 8 & 0,255 & 0,528 & 0,727 \\
\hline Medicamentos e Outros Produtos & 1 & 0,241 & 0,062 & 0,248 \\
\hline Serviços Médico-Hospitalares, Análises e Diagnósticos & 2 & 0,134 & 0,304 & 0,551 \\
\hline Equipamentos & 1 & 0,385 & 0,019 & 0,136 \\
\hline Comércio e Distribuição & 3 & 0,215 & 0,011 & 0,107 \\
\hline Computadores e Equipamentos & 1 & 0,130 & 0,287 & 0,536 \\
\hline Programas e Serviços & 1 & 0,209 & 0,004 & 0,061 \\
\hline Telecomunicações & 4 & 0,221 & 0,314 & 0,560 \\
\hline Energia Elétrica & 32 & 0,282 & 0,960 & 0,980 \\
\hline Água e Saneamento & 3 & 0,260 & 0,035 & 0,187 \\
\hline Gás & 2 & 0,297 & 0,000 & 0,017 \\
\hline Total Geral & 153 & 0,258 & 0,819 & 0,578 \\
\hline
\end{tabular}

Notas: ${ }^{1}$ Variância, ${ }^{2}$ Desvio Padrão

Fonte: Autores (2018).

Contudo pode se afirmar que apesar do alto grau de dispersão do desvio padrão das médias das alíquotas efetivas dos tributos por subsetores, que as empresas realizam alguma forma de gestão tributária, pois o teste não paramétrico de sinais não aceitou a hipótese nula em que a média da ETR é igual a alíquota nominal de $34 \%$.

$\mathrm{H}_{0}: \mathrm{ETR}=0,34$ 
$\mathrm{H}_{1}: \mathrm{ETR}<0,34$

Observa-se na Tabela 2, que a quantidade de sinais negativos foi 1223, evidenciando que nas empresas analisadas neste período de dez anos, ocorreram 1223 observações em que a ETR foi menor que $34 \%$ e apenas 307 casos com sinal positivo.

Tabela 2 - Teste de Sinais

\begin{tabular}{cc}
\hline Sinal & Observações \\
\hline Positivo & 307 \\
Negativo & 1223 \\
Zero & 0 \\
\hline Total & $\mathbf{1 5 3 0}$ \\
\hline
\end{tabular}

Fonte: Autores (2018).

Notou-se que das 1530 observações das 153 empresas no período de 2007 a 2016, possivelmente em algum ou em vários momentos nesse período analisado as empresas possuíram uma alíquota nominal abaixo de 34\%, pois em 1223 situações elas apresentaram a alíquota abaixo de $34 \%$, representado por volta de $80 \%$ do total das observações analisadas.

\subsection{Análise da Regressão com Dados em Painel}

Os resultados da análise da regressão com dados em painel possuem o objetivo de analisar a relação dos indicadores de retorno financeiro das empresas da B3, com o gerenciamento da alíquota efetiva dos tributos sobre o lucro. Para a obtenção dos resultados foi utilizada a ETR para a variável dependente e variáveis explicativas o ROE e ROIC, como variáveis de controle o tamanho da empresa, o grau de alavancagem financeira e o endividamento de longo prazo no período de 2007 a 2016.

Primeiramente, as variáveis foram colocadas em logaritmo para medir a elasticidade das mesmas e depois realizou a regressão para estimar os modelos para dados em painel, pooling, modelo de efeitos fixos e efeitos aleatórios. Como se pode observar na Tabela 4, foram realizados os testes de Chow para testar os modelos entre o pooling e o de efeitos fixos, no qual o modelo selecionado foi o fixo, depois foi realizado o teste de hausman para se testar entre o de efeitos aleatórios e o de efeitos fixos, o melhor modelo selecionado foi fixo e o último teste para retirar todas as dúvidas e concluir sobre o melhor modelo foi o teste de Breusch-Pagan onde se procurou testar o melhor entre o modelo pooling e o de efeitos aleatórios, o modelo selecionado no teste foi o aleatório, portanto o modelo que melhor se adequa de acordo com os testes realizados foi o de efeitos fixos. 
Realizou- se o teste de Wald para heterocedasticidade, onde se rejeitou a hipótese nula de ausência de heterocedasticidade, no entanto a teoria econométrica sugere diferentes opções de tratamento para modelos que apresentam heterocedasticidade em painel. Segundo Gujarati (2006) um destes tratamentos trata-se da estimação das variáveis que compõem o modelo em outros níveis, como por exemplo, $\ln , \log$ entre outros, porém quando não solucionado o problema, Gujarati e Porter (2011 p. 395) “indica o tratamento robusto, em que White mostrou que esta estimativa pode ser realizada de modo que inferências estatísticas válidas assintoticamente (isto é, para amostras grandes) possam ser feitas sobre os verdadeiros valores dos parâmetros".

O problema da heterocedasticidade entre as espacialidades em análise está relacionado ao fato das empresas, com diferentes amostras tratadas nesse estudo, ou seja, muitas empresas analisadas possuem discrepâncias em relação às outras, sendo assim ocorre o aumento do termo de erro, ocasionando um aumento dos resíduos heterocedásticos. Por fim, o teste para identificara autocorrelação (teste de Wooldridge) não identificou a presença de autocorrelação nas variáveis do modelo de dados em painel, que segundo Gujarati e Porter (2011, p. 416) "pressupõe que o termo de erro relacionado a qualquer uma das observações não é influenciado pelo termo de erro de qualquer outra observação".

Segundo Gujarati e Porter (2011, p. 332), "se a multicolinearidade for perfeita os coeficientes de regressão das variáveis serão indeterminados e seus erros padrão, infinitos. Se a multicolinearidade for menos que perfeita, os coeficientes não podem ser estimados com grande precisão ou exatidão”. A Tabela 3 demonstra o teste do fator de inflação da variânciaVIF, como regra prática se o VIF apresentar um valor $\geq 10$ pode se afirmar que a variável possui alto índice de colinearidade e a Tolerância- TOL, representado na Tabela 3 pelo "1/VIF" indica que quanto mais próximo de 1 menores são as chances de multicolinearidade e quanto mais próximo de zero maiores são as chances de multicolinearidade. Como podemos evidenciar as variáveis em análise não apresentam colinearidade e um baixo índice de multicolinearidade.

Tabela 3 - Teste do Fator de Inflação da Variância- VIF

\begin{tabular}{lcc}
\hline & VIF & $\mathbf{1 / V I F}$ \\
\hline roelog & 8.120 & 0.123 \\
roiclog & 4.830 & 0.207 \\
alafinlog & 3.480 & 0.287 \\
tamlog & 1.210 & 0.826 \\
endivlog & 1.180 & 0.845 \\
\hline Média VIF & 3.760 & \\
\hline
\end{tabular}


Dos resultados obtidos por meio da regressão de dados em painel, observou-se de acordo com a Tabela 4, que o $\mathrm{R}^{2}$ within teve uma variação maior que o $\mathrm{R}^{2}$ between. Este resultado indica que as variáveis compostas no modelo possuem uma relação maior ao longo do tempo do que entre elas mesmas.

Tabela 4 - Modelo de Dados em Painel- ETR

\begin{tabular}{|c|c|c|}
\hline \multirow[t]{2}{*}{ Variável } & \multicolumn{2}{|c|}{ Variável Dependente: etrlog } \\
\hline & \multicolumn{2}{|c|}{ Modelo FE } \\
\hline roelog & \multicolumn{2}{|c|}{$\begin{array}{c}-.7327722 * * * * \\
(.1444902)\end{array}$} \\
\hline roiclog & \multicolumn{2}{|c|}{$\begin{array}{c}.6417892 * * * * \\
(.1870074)\end{array}$} \\
\hline tamlog & \multicolumn{2}{|c|}{$\begin{array}{c}-.170712 * * \\
(.0716148)\end{array}$} \\
\hline alafinlog & \multicolumn{2}{|c|}{$\begin{array}{l}.3216651 * * * \\
(.1112498)\end{array}$} \\
\hline endivlog & \multicolumn{2}{|c|}{$\begin{array}{l}.2559174 * \\
(.1411106)\end{array}$} \\
\hline Constante & \multicolumn{2}{|c|}{$\begin{array}{r}3.565002 * * \\
(1.604367)\end{array}$} \\
\hline $\mathbf{N}^{\mathbf{0}}$ obs. & \multicolumn{2}{|c|}{1132} \\
\hline \multicolumn{3}{|l|}{$\mathbf{R}^{2}$} \\
\hline Within & \multicolumn{2}{|c|}{0.1439} \\
\hline Between & \multicolumn{2}{|c|}{0.1354} \\
\hline Overall & \multicolumn{2}{|c|}{0.1348} \\
\hline Teste chow & $F(149.977)=3.69$ & Prob $>F=0.0000$ \\
\hline Teste Breusch-Pagan & Chibar2=180.90 & Prob $>$ chibar $2=0.0000$ \\
\hline Teste hausman & Chi2(5) $=18.11$ & Prob $>$ chi $2=0.0028$ \\
\hline Teste De Wooldridge $^{1}$ & $\mathrm{~F}(1.131)=1.492$ & Prob $>F=0.2241$ \\
\hline Teste de Wald ${ }^{2}$ & $\operatorname{chi} 2(142)=8.1 \mathrm{e}+30$ & Prob $>F=0.0000$ \\
\hline
\end{tabular}

Notas: Nível de Significância: *p $<0.10 ; * * \mathrm{p}<0.05 ; * * * \mathrm{p}<0.01 ; * * * * \mathrm{p}<0.001$

Erro Padrão Robusto entre parênteses

roelog: Logaritmo do retorno sobre o lucro líquido,

roiclog: Logaritmo do retorno sobre o capital investido,

tamlog: Logaritmo do tamanho da empresa,

alafinlog: Logaritmo da alavancagem financeira,

endivlog: Logaritmo do endividamento de longo prazo.

${ }^{1}$ Detecção de autocorrelação em painel,

${ }^{2}$ Teste de Wald para heterocedasticidade em grupo (efeitos fixos).

Fonte: Autores (2018).

Sendo assim o $\mathrm{R}^{2}$ para os dados em painel do modelo fixo foi de 0,1439 , indicando conforme Gujarati e Porter (2011, p. 609) que "o intercepto do modelo de regressão pode diferir entre indivíduos, em reconhecimento ao fato de que cada indivíduo, pode ter características próprias". Ou seja, cada uma das empresas analisadas gerencia a alíquota do imposto sobre o lucro de maneiras distintas uma das outras e que cada empresa possui ROE, ROIC, ativo total, 
alavancagem financeira e endividamento de longo prazo diferente entre elas, pois possuem uma resposta maior de acordo com o tempo, diferindo entre elas na maioria das vezes.

$\mathrm{O}$ resultado do $\mathrm{R}^{2}$ ficou dentro do esperado, pois estudos realizados sobre a ETR não encontraram o $\mathrm{R}^{\mathbf{2}}$ maior do que 0,2500 , pois conforme os resultados de Mota e Leite Filho (2017), que utilizaram a proxy Cash ETR para medir o gerenciamento tributário, os resultados apresentaram um $\mathrm{R}^{2}$ igual 0,1830. Assim como, Armstrong, Blouin e Larckey (2012) que investigaram o tipo de planejamento tributário incluído nos contratos de remuneração dos conselheiros fiscais e o resultado para a variável ETR apresentou um $\mathrm{R}^{2}$ médio de 0,1250 . Nos estudos de Guimarães, Macedo e Cruz (2015) encontraram uma capacidade explicativa do modelo, conforme o $\mathrm{R}^{2}$ ajustado de 0,2369 para a ETR.

\subsubsection{Análise das Variáveis Explicativas}

Os resultados obtidos na análise das variáveis explicativas, afirmam de acordo com a Tabela 4, que o retorno sobre o capital próprio (ROE), retorno sobre o capital investido (ROIC) foram estatisticamente significativos e confirmou a sinalização esperada.

$\mathrm{O}$ indicador de retorno financeiro, mais utilizados nos estudos sobre a alíquota efetiva do imposto sobre o lucro, é o retorno sobre o ativo, Armstroung, Blouin e Larcker (2011) utilizaram o retorno sobre o ativo para controlar a atividade econômica subjacente da empresa e acharam o seguinte resultado para o ROA significativamente positivo, o que indica que as empresas mais rentáveis têm maiores ETRs. Richardson e Lanis (2007) utilizaram o ROA para controlar as mudanças nos resultados operacionais e encontraram uma significativa e positiva associação com a ETR.

Como existem poucos estudos sobre o ROIC em relação à ETR e como a sua relação com o ROA é muita próxima, sendo que ele também indica o retorno sobre os ativos, nesse estudo foram utilizados os resultados de estudos citados acima sobre o ROA, para interpretar os resultados sobre o ROIC. Os resultados encontrados para a variável ROIC foram significativos a níveis inferiores a $1 \%$, indicando que para cada $1 \%$ de aumento do retorno sobre o capital investido a alíquota efetiva do imposto sobre o lucro aumenta em $0,64 \%$. Confirmando o que diz Molina Llopis (2003, p. 201) “as empresas mais lucrativas são aquelas que têm os maiores lucros e, portanto, devem suportar uma carga tributária mais elevada".

A variável ROE apresentou os resultados conforme o esperado, pois apresentou um coeficiente negativo, estatisticamente significativo a níveis inferiores a $1 \%$, sendo que para cada 
$1 \%$ de aumento do retorno sobre o capital próprio a alíquota efetiva do imposto sobre o lucro reduz em $0,73 \%$. Esse fato indica provavelmente que o rendimento dos acionistas está aumentando devido ao aumento da remuneração por desempenho dos diretores.

Conforme o estudo de Minick e Noga (2010) as empresas com maiores remunerações por desempenho para os diretores, investem mais recursos na gestão dos impostos efetivos, o que reduz o montante de impostos que as empresas pagam de longo prazo, resultando em melhorias reais na riqueza dos acionistas. Segundo os resultados de Armstroung, Blouin e Larcker (2011) as empresas fornecem incentivos ao departamento de impostos para mitigar o impacto dos impostos sobre o lucro líquido final.

\subsubsection{Análise das Variáveis de Controle}

Segundo Marconi e Lakatos (2003) a variável de controle é uma variável que o investigador neutraliza ou anula intencionalmente em uma pesquisa, para não interferir na análise da relação entre as variáveis explicativas e dependentes.

A variável alavancagem financeira, conforme a Tabela 4 apresentou que quanto maior o " $\mathrm{x}$ ” maior é o " $\mathrm{y}$ ” e significativa a níveis inferiores a 1\% com a variável dependente ETR, indicando que para cada $1 \%$ de aumento da alavancagem financeira, há um aumento de $0,32 \%$ da taxa de imposto efetiva, então, conforme aumenta o grau de alavancagem, as empresas pagam mais impostos. Esse resultado é contrário a literatura que afirma que a alavancagem reduz a alíquota do imposto sobre o lucro.

Nota-se que esses resultados nos estudos de Huang, Wang e Tsai (2016), Richardson e Lanis (2007), a alavancagem financeira apresentou-se significativamente negativa, sugerindo que as empresas com alta alavancagem financeira têm ETR menores porque as despesas com juros são dedutíveis. Contudo, os resultados de Pohlmann e Iudícibus (2010) sugerem que as empresas que puderem recorrer a capitais de terceiros irão fazê-lo. O limite será justamente o ponto em que os custos decorrentes do financial distress igualarem os benefícios tributários do endividamento.

Confirmando o que diz Guimarães, Macedo e Cruz (2015) que no Brasil uma estrutura alavancada, pode indicar uma maior carga fiscal, pois devido ao baixo desenvolvimento do mercado de capitais, obrigando as empresas a possuírem participações de capitais de terceiros maiores que empresas em outros países em que o mercado de capitais é mais desenvolvido. $\mathrm{O}$ efeito da alavancagem sobre a tributação é praticamente neutralizado. 
O endividamento de longo prazo como podemos observar na Tabela 4, apresentou uma relação positiva e somente significativa a níveis inferiores a $10 \%$ com a variável dependente ETR, contudo a relação é pouco significativa, não podendo plenamente confirmar a relação entre a ETR e o endividamento em longo prazo, por causa da baixa significância do coeficiente.

O tamanho da empresa segundo a Tabela 4 revelou-se negativa e significativa a um nível inferior a $5 \%$ e que para cada $1 \%$ de aumento do tamanho da empresa, há uma redução de 0,17 da alíquota efetiva sobre o lucro, indicando uma possibilidade, que quanto maior o tamanho da empresa menor o imposto sobre o lucro da empresa. Este resultado está de acordo com os estudos de Gupta e Newberry (1997), Richardson e Lanis (2007) e Huang, Wang e Tsai (2016), pois o coeficiente do tamanho da empresa foi significativamente negativo, proporcionando apoio à hipótese do poder político e mostrando que as grandes empresas têm ETR menores.

Os resultados da pesquisa apontam que as variáveis explicativas e de controle estão relacionadas com a variável dependente, sendo que todos os resultados com exceção do endividamento de longo prazo possuíram coeficientes significativos e conforme os estudos sobre a taxa de imposto efetiva.

\section{CONCLUSÃO}

A presente pesquisa utilizou da regressão com dados em painel com o objetivo de analisar a relação dos indicadores de retorno financeiro das empresas da B3, com o gerenciamento da alíquota efetiva dos tributos sobre o lucro. Para a obtenção dos resultados foi utilizada a ETR para a variável dependente e variáveis explicativas o ROE e ROIC, como variáveis de controle o tamanho da empresa, o grau de alavancagem financeira e o endividamento de longo prazo no período de 2007 a 2016.

Este estudo se mostra relevante, pois para o alcance dos resultados utiliza-se elementos das Ciências Contábeis, Ciências do Direito, buscando prover as empresas de informações sobre o gerenciamento tributário, incentivando a utilização das formas legais que existem na legislação brasileira para alcançar a economia tributária. Todas as empresas podem utilizar dos benefícios da gestão tributária, pois como evidenciado nesta pesquisa os tributos também interferem na lucratividade das organizações melhorando ou interferindo de forma negativa na maximização do retorno financeiro.

O objetivo geral da pesquisa analisou a relação dos indicadores financeiros ROE e ROIC com alíquota efetiva do imposto sobre o lucro. A variável ROIC apresentou-se altamente 
significativa a níveis inferiores a $1 \%$ e uma relação positiva com a alíquota efetiva do imposto sobre o lucro, demonstrando possivelmente que as empresas mais rentáveis possuem maiores alíquotas efetivas sobre o lucro, sendo que quanto maior o ROIC maior a carga de impostos sobre o lucro da empresa.

O Retorno sobre o patrimônio líquido (ROE) apresentou uma relação negativa e significativa a níveis inferiores a $1 \%$, mostrando que conforme aumenta o retorno sobre o patrimônio ocorre uma redução da alíquota efetiva do imposto sobre o lucro e uma possível explicação para esse fato é o investimento da organização na remuneração por desempenho dos diretores, que os levam a investirem mais recursos no gerenciamento tributário, gerando um aumento do retorno para os acionistas.

O tamanho das empresas apresentou uma razoável significância a um nível inferior a $5 \%$ e uma relação negativa com a alíquota efetiva sobre o lucro, podendo indicar que quanto maior o tamanho da empresa menor o imposto sobre o lucro da empresa. A alavancagem financeira apresentou uma relação contrária à prevista na literatura, mostrando uma relação positiva e significativa com a alíquota do imposto, sugerindo que quanto maior o grau de alavancagem financeira maior a carga tributária das empresas, indicando que possivelmente no Brasil uma estrutura alavancada, contribui para uma maior carga fiscal.

O endividamento de longo prazo também contrariou as expectativas conforme a literatura e apresentou um resultado positivo e significativo a $10 \%$, e devido ao seu baixo poder explicativo não se pode totalmente confirmar que um maior endividamento de longo prazo gera uma maior alíquota do imposto sobre o lucro.

A identificação do gerenciamento tributário das empresas no Brasil, listadas na B3, evidenciou que as empresas utilizam os benefícios da redução da alíquota efetiva dos tributos sobre o lucro, pois o teste não paramétrico de sinais demonstrou que em $80 \%$ das observações, as alíquotas efetivas dos tributos das empresas analisadas são menores que a alíquota nominal de 34\% das empresas optantes pelo lucro real no período de (2007-2016).

Como limitação da pesquisa pode ser citado algumas das críticas à ETR pelo fato dela incorporar os incentivos fiscais, entretanto no Brasil os benefícios fiscais dependem da decisão das organizações em aproveitá-los ou não. Outro fator limitante é a utilização de variáveis financeiras para serem utilizadas como explicativas, no entanto para estudos futuros sugere-se relacionar a variável dependente com outras variáveis explicativas financeiras e não financeiras. 


\section{REFERÊNCIAS}

ALEXANDRE, R. Direito tributário esquematizado. 10 ed. Rio de Janeiro: Forense, 2016.

ANDRADE, M. M. de. Introdução à metodologia do trabalho científico: elaboração de trabalhos na graduação. 10 ed. São Paulo: Atlas, 2010.

ASSAF NETO, A. Finanças corporativas e valor. 7 ed. São Paulo: Atlas, 2014. ARMSTRONG, C. S.; BLOUIN, J. L.; LARCKER, D. F. The incentives for tax planning. Journal of Accounting and Economics, v. 53, n. 1-2, p. 391-411, 2012.

BALTAGI, B. H. Econometric analysis of pane data. 3 ed. New York: John Wiley \& Sons, 2005.

BRASIL. Decreto Lei $\mathbf{N}^{\circ} \mathbf{2 3 4 1}$, de 1987. Dispõe sobre a correção monetária das demonstrações financeiras, para efeitos de determinar o lucro real, e dá outras providências. Brasília- DF, 1987. Disponível em: http://www.planalto.gov.br/ccivil_03/DecretoLei/Del2341.htm.

BREALEY, R. A.; MYERS, S. C.; ALLEN, F. Princípios de finanças corporativas. 10 ed. Porto Alegre: AMGH, 2013.

CAO, J. Empirical evidence on explicit and implicit corporate tax burdens for public listed companies in the people's republic of China. 2012. $351 \mathrm{f}$. Thesis for the degree of Doctor (Doctorate of Philosophy in Accountancy) - University of Exeter, England, 2012.

DAMODARAN, A. Finanças corporativas: teoria e prática. 2 ed. Porto Alegre: Bookman, 2004.

DYRENG, S. D.; HANLON, M.; MAYDEW, E. L. Long-run corporate tax avoidance. The Accounting Review, v. 83, n. 1, p. 61-82, 2008.

FABRETTI, L. C. Contabilidade tributária. 7 ed. São Paulo: Atlas, 2001.

GITMAN, L. J. Princípios da administração financeira. 12 ed. São Paulo: Pearson Prentice Hall, 2010.

GOMES, A. P. M. A Influência das características da governança corporativa na gestão tributária das empresas brasileiras. 2012. 148 f. Dissertação (Mestrado em Ciências Contábeis) - Universidade Federal de Minas Gerais, Belo Horizonte, 2012.

GUENTHER, D. A.; MATSUNAGA S. R.; WILLIAMS, B. M. Tax avoidance, tax aggressiveness, tax risk and firm risk. Oregon: University of Oregon, Eugene, 2013.

GUIMARÃES, G. O. M.; MACEDO, M. A. S.; CRUZ, C. F. Análise da alíquota efetiva de tributos sobre o lucro no Brasil: um Estudo com foco na ETRt e na ETRc. Enfoque Reflexão Contábil, v. 35, n. 1, p. 1-16, 2016.

GUJARATI, D. N. Econometria básica. Rio de Janeiro: Elsevier, 2006. 
GUJARATI, D. N.; PORTER, D. C. Econometria básica. 5 ed. Porto Alegre: AMGH, 2011.

GUPTA, S.; NEWBERRY, K. Determinants of the variability in corporate effective tax rates: evidence from longitudinal data. Journal of Accounting and Public Policy, v. 16, n. 1, p. 134, 1997.

HIGUCHI, H. Imposto de renda das empresas: interpretação e prática. 39 ed. São Paulo: IR Publicações, 2014.

HUANG, M. C.; WANG, Y. H.; TSAI, Y. C. The effects of tax reform on corporate effective tax rates: moderated by industry and firm-specific characteristics. Airit Library, v. 35, n. 4, p. 147-164, 2016.

LARSON, R.; FARBER, B. Estatística aplicada. 4 ed. São Paulo: Pearson Prentice Hall, 2010 .

MARCONI, M. de A.; LAKATOS, E. M. Fundamentos de metodologia científica. 5 ed. São Paulo: Atlas, 2003.

MARTINS, G. de A.; THEÓPHILO, C. R. Metodologia da investigação científica para ciências sociais aplicadas. 2 ed. São Paulo: Atlas, 2009.

MINARDI, J. Manual do direito tributário. 2 ed. Salvador: JusPODIVM, 2015.

MINNICK, K.; NOGA, T. Do corporate governance characteristics influence tax management? Journal of Corporate Finance, v. 16, n. 5, p. 703- 718, 2010.

MOLINA LLOPIS, R. La evolución de la presión fiscal enlas pymes: una aproximación a suIncidencia sobre la situación financiera de las empresas de la comunidad valenciana. 2003. 386 f. Tesis Doctoral (Tesis Doctoralen Contabilidad) - Universitat de València, Spain, 2003.

MOTA, S. L.; LEITE FILHO, P. A. M. Fatores determinantes do gerenciamento tributário no Brasil: análise a partir da proxy de elisão fiscal long-run cash ETR. In: XVII CONGRESSO USP CONTROLADORIA E CONTABILIDADE. Anais [...]. São Paulo, 2017.

PADOVEZE, C. L. Introdução à administração financeira: texto e exercícios. 2 ed. São Paulo: Cengage Learning, 2010.

PÉREZ, J. I. C.; SERER, G. L.; LLOPIS, R. M. Variables económico-financeiras que inciden sobre La pressión fiscal soportada por las empresas: efectos de la reforma fiscal de 15 anos em las empresas de La comunidad valenciana. Revista Española de Financiación y Contabilidad, España, v. 34, n. 127, p. 875-897, 2005.

POHLMANN, M. C.; IUDÍCIBUS, S. de. Relação entre a tributação dol e a estrutura de capital das grandes empresas no Brasil. Revista Contabilidade \& Finanças, v. 21, n. 53, p. $1-25,2010$.

REGO, S. O. Tax-avoidance activities of U.S. multinational corporations. Contemporary Accounting Research, v. 20, n. 4, p. 805-833, 2003. 
RICHARDSON, G.; LANIS, R. Determinants of the variability in corporate effective tax rates and tax reform: evidence from Australia. Journal of Accounting and Public Policy, v. 26, n. 6, p. 689-704, 2007.

SEIGFRIED, J. J. The relationship between economic structure and the effect of political influence: empirical evidence from the corporation income tax program. 1972. $342 \mathrm{f}$.

Dissertation, University of Wisconsin, Madison, 1972.

SHEVLIN, T. J. A critique of plesko's 'an evaluation of alternative measures of corporate tax rates'. California: University of California-Irvine, 1999.

SIQUEIRA, E. B.; CURY, L. K. P.; GOMES, T. S. Planejamento tributário. Revista CEPPG, v. 25, n. 25, p. 184- 196, 2011.

TANG, T. Y. H. Book-tax differences, a proxy for earnings management and tax management - empirical evidence from China. Canada: Brock University, 2005.

UTZIG, M. J. S. et al. Taxa de imposto efetiva sobre a renda nas empresas do Mercosul. Revista de Contabilidade do Mestrado em Ciências Contábeis da UERJ, v. 19, n.2, p. 4057, 2014.

VELLO, A. P. C.; MARTINEZ, A. L. Planejamento tributário eficiente: uma análise de sua relação com o risco de mercado. Revista Contemporânea de Contabilidade, v. 11, n. 23, p. 117- 140, 2014.

WOOLDRIDGE, J. M. Introdução à econometria: uma abordagem moderna. São Paulo: Cengage Learning, 2011.

YOUNG, L. H. B. Lucro real. 6 ed. Curitiba: Juruá, 2012.

ZIMMERMAN, J. Taxes and firm size. Journal of Accounting and Economics, v. 5, p.119149, 1983.

\section{DADOS DOS AUTORES}

\section{Tiago de Jesus Mendes}

E-mail: tjmendes91@gmail.com

Curriculum Lattes: http://lattes.cnpq.br/2981063094801021

Mestrado Profissionalizante em Desenvolvimento Econômico e Estratégia Empresarial pela Universidade Estadual de Montes Claros; bacharel em Administração pela Universidade Estadual de Montes Claros. Atualmente é consultor em gestão empresarial em micro e pequenas empresas.

\section{Ilva Ruas Abreu}

E-mail: ilvaruas@gmail.com

Curriculum Lattes: http://lattes.cnpq.br/2818599110543545 
Doutorado em História pela Universidade Federal de Minas Gerais; mestrado em Administração pela Universidade Federal de Santa Catarina; bacharel em Ciências Econômicas pela Fundação Norte-Mineira de Ensino Superior. Atualmente é professora titular do curso de Ciências Econômicas e dos programas de pós-graduação stricto sensu/mestrado em História e Desenvolvimento Econômico e Estratégia Empresarial da Universidade Estadual de Montes Claros. Tem experiência na área de História com ênfase em História do Brasil, Economia e Administração atuando principalmente nos seguintes temas: desenvolvimento econômico, desenvolvimento regional, norte de minas, história das elites brasileiras e metodologia da pesquisa em economia. Vice-reitora da Universidade Estadual de Montes Claros.

\section{Felipe Fróes Couto}

E-mail: felipe.froes@outlook.com

Curriculum Lattes: http://lattes.cnpq.br/1542783014894190

Doutorado e mestrado em Administração pela Universidade Federal de Minas Gerais; bacharel em Administração pela Universidade Estadual de Montes Claros e bacharel em Direito pela Faculdade Integrada Pitágoras; MBA em Gestão Financeira, Controladoria e Auditoria pela Faculdade IBS/FGV e parceria com a Fordham Law School (NY-EUA). Atua nos campos da Administração Pública, Estratégia(s) e Estudos Organizacionais. 